Ribogospod. nauka Ukr., 2016; 2(36): 65-72

DOI: http://dx.doi.org/10.15407/fsu2016.02.065

UDC 597-115:639.371.13

\title{
PECULIARITIES OF THE GENETIC STRUCTURE OF RAINBOW TROUT (ONCORHYNCHUS MYKISS) GROUPS AT THE FISH FARM "SLOBODA BANILOV", CHERNIVTSI REGION
}

\author{
P. Mendrishora, mendryshora@mail.ru, Institute of Fisheries NAAS, Kyiv \\ T. Nagornjuk, achtaan@ukr.net, Institute of Fisheries NAAS, Kyiv \\ S. Tarasjuk, tarasyuk@if.org.ua, Institute of Fisheries NAAS, Kyiv
}

Purpose. Study of the peculiarities of the genetic structure based on genetic-biochemical markers in age-1+ and 2+ rainbow trout of the fish farm "Sloboda Banilov", Chernivtsi region

Methodology. We used the methods of vertical polyacrylamide and horizontal starch electrophoresis with own modification. Sampling of biological material and histochemical and staining of gel plates were performed according to generally accepted methods. The frequency of allele and genotypic variants were calculated, actual and expected level of heterozygosis for each individual locus and the level of mean heterozygosis per locus were determined, Wright F fixation index was calculated. Statistical processing of experimental data was performed with the use "Biosys1 " software.

Findings. We performed an analysis of the genetic structure of rainbow trout (Oncorhynchus mykiss) groups with the use of genetic-biochemical markers - esterase loci (EST, EC 3.1.1.1), carboanhydrase (CA, EC 4.2.1.1), isocitrate dehydrohenase (IDH, EC1.1.1.41), superoxide dismutase (SOD, EC 1.15.1.1). We showed the peculiarities of the distribution of allele variants of the studied loci of rainbow trout. The genotypic composition of biochemical system loci supposed the surplus of fish with heterozygous genotypes by SOD locus in age-1+ fish $\left(G_{o}=26 ; G_{e}=15.3\right), \chi^{2}=15.4, P<0.001$, as well as by EST loci $\left(G_{0}=22 ; G_{e}=14.6\right), \chi^{2}=7.9, P<0.01$ u SOD $\left(G_{o}=22 ; G_{e}=14.9\right), \chi^{2}=6.8, P<0.01$ in age- $2+$ fish. It was found that the investigated groups of fish were characterized by high level of heterozygosis by SOD locus ( $\left.H_{0}=73.3-86.7 \%\right)$ compared to the expected value $\left(H_{e}=49-50 \%\right), P<0.001-0.01$. We observed insignificant prevalence of the actual level of mean heterozygosis over the expected values in age-1+ fish $\left(H_{0}=59.9 \%, H_{e}=49.7 \%, F=-0.205\right)$ and age-2+ rainbow trout $\left(H_{o}=68.3 \%, H_{e}=48.8 \%\right.$, $F=-0.399)$ that indicate on the necessity to stabilize their genetic structure.

Originality. For the first time we performed an assessment of the genetic structure based on genetic-biochemical markers and calculated the level of heterozygosis in age-1+and 2+ rainbow trout reared at the fish farm "Sloboda Banyliv" of Chernivtsi region.

Practical value. Results of the study can be used for solving various tasks of group and individual identification of populations when forming the stocks for optimizing their genetic structure. Experimental data of the frequency of allele and genotype distribution will be used for studying the effect of artificial selection factors in the process of rainbow trout adaptation to new living conditions.

Keywords: rainbow trout, genetic structure, locus, alleles, genotype, heterozygosis.

\section{PROBLEM STATEMENT AND ANALYSIS OF LAST ACHIEVEMENTS AND PUBLICATIONS}

Genetic structure of a population is determined, above all, by the diversity of its gene pool, which includes both the general species properties and genetic features during the adaptation of the population to specific conditions of its existence. This

(C) P. Mendrishora, T. Nagornjuk, S. Tarasjuk, 2016 
aspect of genetic structure also involves the degree of individual and interbreed variability. Many scientists have dealt with the problems of the genetic preservation and restoration of fish populations. Foreign authors studied the genetic characteristics of rainbow trout based on monomorphic and polymorphic allozyme loci, determined that the diagnostic loci for establishing possible hybridization between Oncorhynchus gilae and rainbow trout were $A D H, C K-C 2, F H-1, G A P D H-4, L D H-C, P E P B, P G K-2$ and $P G M-1[1,2]$.

Some authors investigated trout genetic diversity of the breeding farm "Adler" in order to optimize the gene pool structure of their brood stocks. Were analyzed seven loci: aspartate aminotransferase (AAT-3), glycerophosphate dehydrogenase (GPD-1), isocitrate dehydrogenase (IDHP 3, IDHP-4), lactate dehydrogenase (LDH-5), phosphoglucomutase (PGM-1), superoxide dismutase (SOD-1) with the use of electrophoretic analysis of tissue homogenates. Evaluation of fish in terms of protein biochemical polymorphism indicated on the genetic proximity between Adler trout and Donaldson trout. Kamloops trout is characterized by the highest values of genetic distances from other species. The indicators of genetic diversity (average heterozygosis, percentage of polymorphic loci and number of alleles per locus) in Donaldson trout were characterized by low variability compared with Adler trout and kamloops trout groups [3].

Many foreign researchers studied the tissues specificity in rainbow trout and genotypic composition of phosphoglucomutase [4], isocitrate dehydrogenase [2, 5], transferrin, $\alpha$-glycerophosphate dehydrogenase, tetrazolium oxidase loci [6].

Some authors studied the genetic variability of rainbow trout lines of different age groups reared in Ireland. They observed significant differentiations of allelic composition of enzyme systems in different age groups, but the rate of average heterozygosis was characterized by high stability in all samples [7].

\section{HIGHLIGHT OF THE EARLIER UNRESOLVED PARTS OF THE GENERAL PROBLEM. AIM OF THE STUDY}

Molecular genetic methods have been used to study many kinds of livestock animals. One of the least studied objects are fish, the population-genetic characteristics for which are virtually absent. Therefore, one of important issues in fish farming is to assess the genetic variability of rainbow trout stocks from fish farms of Ukraine, which is necessary to monitor the changes in genetic potential and contains information on processes occurring in their populations. The aim of this work was to study the genetic structure features of rainbow trout (Oncorhynchus mykiss) groups at the farm "Sloboda Banyliv", Chernivtsi, region based on genetic and biochemical systems.

\section{MATERIALS AND METHODS}

Blood samples were taken from caudal vein of age-1+ and 2+ rainbow trout from the fish farm "Sloboda Banyliv", Chernivtsi region. Heparin 25 IU per $1 \mathrm{ml}$ of blood was used as a preservative. Blood was fractionated by centrifugation for $10 \mathrm{~min}$. at $3500 \mathrm{rpm}$. The obtained plasma and erythrocytes fractions were placed in test tubes and stored at $-18{ }^{\circ} \mathrm{C}$. The electrophoretic distribution of blood enzymes was performed in starch and polyacrylamide gels $[8,9,10]$ with own modifications, followed by histochemical staining of gel plates [11, 12]. Following genetic and biochemical markers were investigated: esterase (EST, EC 3.1.1.1), carbonic anhydrase (Ca, 
EC 4.2.1.1), isocitrate dehydrogenase (IDH, EC 1.1.1.41), superoxide dismutase (SOD, EC 1.15.1.1) loci. The statistical analysis of the research results was carried out in "Biosys-1" software.

\section{STUDY RESULTS AND THEIR DISCUSSION}

The aim of this work was to investigate the genetic structure of rainbow trout (Oncorhynchus mykiss) groups from the fish farm "Sloboda Banyliv", Chernivtsi region, based on genetic and biochemical systems. For age- $1+$ and $2+$ rainbow trout, we showed the peculiarities of the distribution of slowly and quickly migrating allelic variants of the investigated loci, the frequencies of which were very similar and did not differ significantly (tab. 1).

Table 1. Allele frequency of genetic and biochemical marker in rainbow trout

\begin{tabular}{|c|c|c|c|c|c|c|c|c|}
\hline \multirow{3}{*}{ Studied groups } & \multicolumn{8}{|c|}{ Frequency of allelic loci of genetic and biochemical systems } \\
\hline & \multicolumn{2}{|c|}{ EST } & \multicolumn{2}{|c|}{ CA } & \multicolumn{2}{|c|}{ IDH } & \multicolumn{2}{|c|}{ SOD } \\
\hline & $\mathbf{F}$ & $\mathbf{S}$ & $\mathbf{F}$ & $\mathbf{S}$ & $\mathbf{F}$ & $\mathbf{S}$ & $\mathbf{F}$ & $\mathbf{S}$ \\
\hline $\begin{array}{l}\text { Rainbow trout } \\
\text { (age-1+, } n=30 \text { ) }\end{array}$ & 0.446 & 0.554 & 0.450 & 0.550 & 0.517 & 0.483 & 0.500 & 0.500 \\
\hline $\begin{array}{l}\text { Rainbow trout } \\
\text { (age-2+, n=30) }\end{array}$ & 0.400 & 0.600 & 0.500 & 0.500 & 0.400 & 0.600 & 0.567 & 0.433 \\
\hline
\end{tabular}

The distribution of phenotypic variants of the investigated loci has been provided (tab. 2). For SOD locus, age-1+ rainbow trout was characterized by significant predominance of heterozygous genotypes FS - 86\% compared to the expected $51 \%$, FF and SS homozygotes were $7 \%$. Based on other studied loci, age-1+ group was characterized by statistically significant balance between the observed and expected heterozygous genotypes.

Table 2. Distribution of genotypic variations in rainbow trout (age-1+)

\begin{tabular}{|c|c|c|c|c|c|}
\hline Locus & Genotype & $G_{o}$ & $G_{e}$ & $x^{2}$ & $\mathbf{P}$ \\
\hline & $\mathrm{FF}$ & 6 & 5.455 & & \\
\hline \multirow[t]{3}{*}{ EST } & FS & 13 & 14.091 & 0.174 & $>0.05$ \\
\hline & SS & 9 & 8.455 & & \\
\hline & $\mathrm{FF}$ & 5 & 5.949 & & \\
\hline \multirow[t]{3}{*}{$C A$} & FS & 17 & 15.102 & 0.491 & $>0.05$ \\
\hline & SS & 8 & 8.949 & & \\
\hline & $\mathrm{FF}$ & 8 & 7.881 & & \\
\hline \multirow[t]{3}{*}{ IDH } & FS & 15 & 15.237 & 0.008 & $>0.05$ \\
\hline & SS & 7 & 6.881 & & \\
\hline & $\mathrm{FF}$ & 2 & 7.373 & & \\
\hline \multirow[t]{2}{*}{$S O D$} & FS & 26 & 15.254 & 15.401 & $<0.001$ \\
\hline & SS & 2 & 7.373 & & \\
\hline
\end{tabular}

Note: here and in the following table $G_{o}$ - the actual number of genotypes, $G_{e}$ - expected number of genotypes 
In age-2+ group of rainbow trout (Tab. 3), the imbalanced state based on the number of observed (73\%) and expected (50\%) FS genotypes was observed for EST and SOD loci, $\mathrm{P}<0.01$.

Table 3. Distribution of genotypic variants in rainbow trout (age-2+)

\begin{tabular}{|c|c|c|c|c|c|}
\hline Locus & Genotype & $G_{o}$ & $G_{e}$ & $x^{2}$ & $\mathbf{P}$ \\
\hline & $\mathrm{FF}$ & 1 & 4.678 & & \\
\hline \multirow[t]{3}{*}{$E S T$} & FS & 22 & 14.644 & 7.854 & $<0.01$ \\
\hline & SS & 7 & 10.678 & & \\
\hline & $\mathrm{FF}$ & 5 & 7.373 & & \\
\hline \multirow[t]{3}{*}{$C A$} & FS & 20 & 15.254 & 3.004 & $>0.05$ \\
\hline & SS & 5 & 7.373 & & \\
\hline & $\mathrm{FF}$ & 3 & 4.678 & & \\
\hline \multirow[t]{3}{*}{ IDH } & FS & 18 & 14.644 & 1.635 & $>0.05$ \\
\hline & SS & 9 & 10.678 & & \\
\hline & $\mathrm{FF}$ & 6 & 9.508 & & \\
\hline \multirow[t]{2}{*}{$S O D$} & FS & 22 & 14.983 & 6.815 & $<0.01$ \\
\hline & SS & 2 & 5.508 & & \\
\hline
\end{tabular}

Heterogeneity is one of the most important characteristics of populations. We studied the level of genetic variation in the investigated loci (Tab. 4). The group of age$1+$ rainbow trout had a significant predominance of heterozygosis level based on SOD locus with a value of $86.7 \%$ compared with the expected $50 \%$, which was reflected by Wright fixation index $\mathrm{F}=-0.733$. Because this group was characterized by a balanced state based on other investigated loci, the observed $(59.9 \%)$ and expected $(49.7 \%)$ values of the average heterozygosis level were very similar.

Table 4. Mean heterozygosis level in rainbow trout groups

\begin{tabular}{||c|c|c|c|c|c|c||}
\hline Age group & $\boldsymbol{H}$ & $\boldsymbol{E S T}$ & $\boldsymbol{C A}$ & $\boldsymbol{I D H}$ & SOD & $\boldsymbol{H}_{\text {mean }}$ \\
\hline Rainbow trout & $H_{o}$ & 0.464 & 0.567 & 0.500 & 0.867 & $0.599 \pm 0.092$ \\
(age-1+) & $H_{e}$ & 0.494 & 0.495 & 0.499 & 0.500 & $0.497 \pm 0.001$ \\
& $F$ & 0.061 & -0.145 & -0.001 & -0.733 & -0.205 \\
\hline & $H_{0}$ & 0.733 & 0.667 & 0.600 & 0.733 & $0.683 \pm 0.032$ \\
Rainbow trout & $H_{e}$ & 0.480 & 0.500 & 0.480 & 0.491 & $0.488 \pm 0.005$ \\
(age-2+) & $F$ & -0.528 & -0.333 & -0.250 & -0.493 & -0.399 \\
\hline
\end{tabular}

Note: $\mathrm{H}_{\mathrm{o}}$ - observed level of heterozygosis; $\mathrm{H}_{\mathrm{e}}$ - expected level of heterozygosis; $\mathrm{F}-$ fixation index

In age-2+ group, the observed level of heterozygosis level significantly surpassed the expected one based on two genetic and biochemical systems (Tab. 4). E.g., the genetic variability of EST and SOD loci was $73.3 \%$ compared to the expected values of 
$48 \%$ and $49.1 \%$ for the fixation indices $\mathrm{F}=-0.528$ and -0.493 , respectively, for the aforementioned two loci. Hence, the detected mean heterozygosis level was significantly higher (68.3\%) than the expected one (48.8\%).

\section{CONCLUSION AND PERSPECTIVES OF FURTHER DEVELOPMENT}

We performed an analysis of the genetic structure of age-1+ and $2+$ rainbow trout based on EST, CA, IDH, and SOD loci. In the investigated age groups, we found high levels of heterozygosis for SOD locus $\left(\mathrm{H}_{0}=73.3-86.7 \%\right)$, in contrast to the expected value $\left(\mathrm{H}_{\mathrm{e}}=49-50 \%\right), \mathrm{P}<0.001-0.01$. We determined the level of mean heterozygosis based on the studied loci, the observed value of which was $59.9 \%$ in age-1+ trout and $68.3 \%$ in age- $2+$ trout with the expected level of $48.8-49.7 \%$ that indicates on the need to stabilize the genetic structure of fish for markers.

\section{BIBLIOGRAPHY}

1. Leary R. F. Genetic issues in the conservation and restoration of the endangered Gila trout / R. F. Leary, F. W. Allendorf // University of Montana Wild Trout and Salmon Genetics Laboratory Report 98/1. — University of Montana, 1998. - 29 p.

2. A consolidated linkage map for rainbow trout (Oncorhynchus mykiss) / K. M. Nichols, W. P. Young, R. G. Danzmann [et al.] // Animal genetics. - 2003. - Vol. 34(2). - P. 102-115.

3. Бабий В. А. Использование биологических и технологических особенностей коллекции пород радужной форели племзавода «Адлер» для комплектования маточных стад рыбхозов [Текст] : автореф. дисс. на соискание учен. степени канд. с.-х. наук : 06.02.01 - разведение, селекция, генетика и воспроизводство сельскохозяйственных животных / В. А. Бабий. - Краснодар, 1998. — 25 с.

4. Allendorf F. W. Identification of a gene regulating the tissue expression of a phosphoglucomutase locus in rainbow trout / F. W. Allendorf, K. L. Knudsen, S. R. Phelps. - Genetics. - 1982. - Vol. 102. - P. 259-268.

5. Allendorf F. W. Gene duplication within the family Salmonidae: disomic inheritance of two loci reported to be tetrasomic in rainbow trout / F. W. Allendorf, F. M. Utter. - Genetics. — 1973. - Vol. 74. - P. 647-654.

6. Utter F. M. Biochemical variants in pacific salmon and rainbow trout: their inheritance and application in population studies / F. M. Utter, H. O. Hodgins, F. W. Allendorf, A. G. Johnson, J. L. Mighell. - Genetics and Mutagenesis of Fish. - 1973. - Vol. 7. - P. 329-339.

7. Butler A. Genetic differences between successive year classes of two strains of reared rainbow trout, Oncorhynchus mykiss (Walbaum) / A. Butler, T. F. Cross. Aquacult. Res. — 1996. — Vol. 27, № 9. — P. 643-649.

8. Тарасюк C. I. Молекулярно-генетичні дослідження в рибництві / C. I. Тарасюк, I. I. Грициняк. - К. : Аграрна наука, 2013. - 310 с.

9. Davis B. J. Disc electrophoresis. II. Method and application to human serum proteins / B. J. Davis // Ann. N. Y. Acad. Sci. - 1964. - Vol. 121. - P. 404408.

10. Harris H. Handbook of enzyme electrophoresis in human genetics / Harris H., Hopkinson D. // Amsterdam : North-Holland Publ. Comp., 1976. - 620 p.

11. Кирпичников В. С. Генетика и селекция рыб / Кирпичников В. С. - Л. : Наука, 1987. - 520 с. 
12. Генетика изоферментов / [Корочкин Л. И., Серов О. Л., Пудовник А. И. и др.]. - М. : Наука, 1977. — 275 с.

\section{REFERENCES}

1. Leary, R. F., \& Allendorf, F. W. (1998). Genetic issues in the conservation and restoration of the endangered Gila trout. University of Montana Wild Trout and Salmon Genetics Laboratory Report 98/1. University of Montana.

2. Nichols, K. M., Young, W. P., Danzmann, R. G., Robison, B. D., Rexroad, C., Noakes, M., Phillips, R. B., Bentzen, P., Spies, I., Knudsen, K., Allendorf, F. W., Cunningham, B. M., Brunelli, J., Zhang, H., Ristow, S., Drew, R., Brown, K. H., Wheeler, P. A. \& Thorgaard, G. H. (2003). A consolidated linkage map for rainbow trout (Oncorhynchus mykiss). Animal genetics, 34 (2), 102-115.

3. Babiy, V. A. (1998). Ispol'zovanie biologicheskikh i tekhnologicheskikh osobennostey kollektsii porod raduzhnoy foreli plemzavoda "Adler" dlya komplektovaniya matochnykh stad rybkhozov. Extended abstract of candidate's thesis. Krasnodar.

4. Allendorf, F. W., Knudsen, K. L., \& Phelps, S. R. (1982). Identification of a gene regulating the tissue expression of a phosphoglucomutase locus in rainbow trout. Genetics, 102, 259-268.

5. Allendorf, F. W., \& Utter, F. M. (1973). Gene duplication within the family Salmonidae: disomic inheritance of two loci reported to be tetrasomic in rainbow trout. Genetics, 74, 647-654.

6. Utter, F. M., Hodgins, H. O., Allendorf, F. W., Johnson, A. G., \& Mighell, J. L. (1973). Biochemical variants in pacific salmon and rainbow trout: their inheritance and application in population studies. Genetics and Mutagenesis of Fish, 7, 329339.

7. Butler, A., \& Cross, T. F. (1996). Genetic differences between successive year classes of two strains of reared rainbow trout, Oncorhynchus mykiss (Walbaum). Aquacult. Res., 27, 643-649.

8. Tarasiuk, S. I., \& Hrytsyniak, I. I. (2013). Molekuliarno-henetychni doslidzhennia v rybnytstvi. Kyiv : Ahrarna nauka.

9. Davis, B. J. (1964). Disc electrophoresis. II. Method and application to human serum proteins. Ann. N. Y. Acad. Sci., 121, 404-408.

10. Harris, H., Hopkinson, D. (1976). Handbook of enzyme electrophoresis in human genetics. Amsterdam: North-Holland Publ. Comp., 620.

11. Kirpichnikov, V. S. (1987). Genetika i selektsiya ryb. Leningrad : Nauka.

12. Korochkin, L. I., Serov, O. L., Pudovnik, A. I., Aronshtam, A. A., Polyakova, E. V., Maletskiy, S. I., \& Borkin, L. V. (1977). Genetika izofermentov. Moskva : Nauka.

\section{ОСОБЛИВОСТІ ГЕНЕТИЧНОЇ СТРУКТУРИ ГРУП РАЙДУЖНОÏ ФОРЕЛІ (ONCORHYNCHUS MYKISS) ГОСПОДАРСТВА «СЛОБОДА БАНИЛІВ» ЧЕРНІВЕЦЬКОЇ ОБЛ.}

п. Д. Мендришора, mendryshora@mail.ru, Інститут рибного господарства НАAН, М. Київ

T. А. Нагорнюк, achtaan@ukr.net, Інститут рибного господарства НАAН, м. Київ

C. І. Тарасюк, tarasyuk@if.org.ua, Інститут рибного господарства НАAН, м. Київ 
Мета. Вивчення особливостей генетичної структури за генетико-біохімічними маркерами у 1+ і 2+ особин райдужної форелі господарства «Слобода Банилів» Чернівецької обл.

Методика. В дослідженнях використовували методи вертикального поліакриламідного та горизонтального крохмального електрофорезів з власними модифікаціями. Відбір зразків біологічного матеріалу та гістохімічне фарбування гелевих пластин проводили за загальноприйнятими методиками. Розраховано частоту алельних і генотипових варіантів, визначено фактичний і очікуваний рівні гетерозиготності за кожним окремим локусом та рівень середньої гетерозиготності на локус, розрахований індекс фіксації Райта $F$. Статистичне опрацювання експериментальних даних виконували з використанням програми «Biosys-1».

Результати. Виконано аналіз генетичної структури груп райдужної форелі (Oncorhynchus mykiss) з використанням генетико-біохімічних маркерів - локусів естерази (EST, КФ 3.1.1.1), карбоангідрази (CA, КФ 4.2.1.1), ізоцитратдегідрогенази (IDH, КФ 1.1.1.41), супероксиддисмутази (SOD, КФ 1.15.1.1). У райдужної форелі показано особливості розподілу алельних варіантів досліджуваних локусів. Генотиповий склад локусів біохімічних систем передбачав надлишок особин з гетерозиготними генотипами за локусом SOD у $1+$ особин $\left(G_{0}=26 ; G_{e}=15,3\right), \chi^{2}=15,4, P<0,001$, а також локусами $E S T\left(G_{o}=22 ; G_{e}=14,6\right), \chi^{2}=7,9, P<0,01$ i SOD $\left(G_{0}=22 ; \quad G_{e}=14,9\right), \quad \chi^{2}=6,8, \quad P<0,01$ у 2+ особин. Встановлено, що досліджені групи характеризувались високим рівнем гетерозиготності за локусом SOD $\left(H_{o}=73,3-86,7 \%\right)$, порівняно з очікуваним значенням $\left(H_{e}=49-50 \%\right), P<0,001-0,01$. Спостерігалась незначна перевага фрактичного рівня середньої гетерозиготності над очікуваним у 1+ особин $\left(H_{o}=59,9 \%, H_{e}=49,7 \%, F=-0,205\right)$ і $2+$ особин райдужної форелі $\left(H_{o}=68,3 \%, H_{e}=48,8 \%, F=-0,399\right)$, що вказувало на необхідність стабілізації генетичної структури.

Наукова новизна. Вперше виконано оцінку генетичної структури за генетикобіохімічними маркерами та розрахований рівень гетерогенності у груп 1+ i 2+ особин райдужної форелі, які вирощуються у господарстві «Слобода Банилів» Чернівецької обл.

Практична значимість. Результати досліджень можуть бути використані у вирішенні різноманітних завдань групової та індивідуальної ідентифікації популяцій при формуванні стад з метою оптимізації генетичної структури. Експериментальні дані розподілу частот алелей і генотипів будуть використані для вивчення впливу фракторів итучного добору у процесі адаптації райдужної форелі до нових умов існування.

Ключові слова: райдужна форель, генетична структура, локус, алелі, генотип, гетерозиготність.

\title{
ОСОБЕННОСТИ ГЕНЕТИЧЕСКОЙ СТРУКТУРЫ ГРУПП РАДУЖНОЙ ФОРЕЛИ (ONCORHYNCHUS MYKISS) ХОЗЯЙСТВА «СЛОБОДА БАНИЛОВ» ЧЕРНОВИЦКОЙ ОБЛ.
}

\author{
П. Д. Мендришора, mendryshora@mail.ru, Институт рыбного хозяйства НАAН, \\ г. Киев \\ T. А. Нагорнюк, achtaan@ukr.net, Институт рыбного хозяйства НАAН, г. Киев \\ С. И. Тарасюк, tarasyuk@if.org.ua, Институт рыбного хозяйства НАAН, г. Киев
}

Цель. Изучение особенностей генетической структуры по генетико-биохимическим маркерам у 1+ и 2+ особей радужной форели хозяйства «Слобода Банилов» Черновицкой обл.

Методика. В исследованиях использовали методы вертикального полиакриламидного и горизонтального крахмального электрофорезов с собственными модификациями. Отбор образцов биологического материала и гистохимическое окрашивание гелевых пластин проводили по общепринятым методикам. Рассчитана частота аллельных и генотипических вариантов, определены фактический и ожидаемый уровни гетерозиготности по каждому отдельному локусу и уровень средней гетерозиготности на локус, рассчитан индекс 

GROUPS AT THE FISH FARM "SLOBODA BANILOV», CHERNIVTSI REGION

фиксации Райта F. Cтатистическую обработку экспериментальных данных выполняли с использованием программы «Віоsys-1».

Результаты. Выполнен анализ генетической структуры групп радужной форели (Oncorhynchus mykiss) c использованием генетико-биохимических маркеров - локусов эстеразы (EST, КФ 3.1.1.1), карбоангидразы (СА, КФ 4.2.1.1), изоцитратдегидрогеназы (IDH, КФ 1.1.1.41), супероксиддисмутазы (SOD, КФ 1.15.1.1). у радужной форели показаны особенности распределения аллельных вариантов исследуемых локусов. Генотипический состав локусов биохимических систем предполагал избыток особей с гетерозиготными генотипами по локусу SOD у $1+$ особей $\left(G_{0}=26 ; G_{e}=15,3\right), \chi^{2}=15,4, P<0,001$, а также локусам EST $\left(G_{o}=22 ; G_{e}=14,6\right), \chi^{2}=7,9, P<0,01$ и $\operatorname{SOD}\left(G_{0}=22 ; G_{e}=14,9\right), \chi^{2}=6,8, P<0,01$ у $2+$ особей. Установлено, что исследуемые группы характеризовались высоким уровнем гетерозиготности по локусу SOD ( $\left.H_{o}=73,3-86,7 \%\right)$, в сравнении с ожидаемым значением ( $\left.H_{e}=49-50 \%\right), P<0,001-0,01$. Наблюдалось незначительное преобладание фрактического уровня средней гетерозиготности над ожидаемым у $1+$ особей $\left(H_{0}=59,9 \%, H_{e}=49,7 \%, F=-0,205\right)$ и 2+ особей радужной форели $\left(H_{0}=68,3 \%, H_{e}=48,8 \%, F=-0,399\right)$, что свидетельствовало о необходимости стабилизации их генетической структуры.

Научная новизна. Впервые выполнена оценка генетической структуры по генетикобиохимическим маркерам и рассчитан уровень гетерогенности у групп $1+$ и 2+ особей радужной форели, которые выращиваются в хозяйстве «Слобода Банилов» Черновицкой обл.

Практическая значимость. Результаты исследований могут быть использованы при решении разнообразных задач групповой и индивидуальной идентификации популяций при формировании стад с целью оптимизации генетической структуры. Экспериментальные данные распределения частот аллелей и генотипов будут использованы для изучения влияния факторов искусственного отбора в процессе адаптации радужной форели к новым условиям существования.

Ключевые слова: радужная форель, генетическая структура, локус, аллели, генотип, гетерозиготность. 